\title{
PROJETO PLUG-IN: UMA PERSPECTIVA DE MOBILIDADE HABITACIONAL
}

\author{
Amanda Soares Fardelône \\ Universidade Estadual Paulista "Julio de Mesquita Filho" \\ amandafardelone@gmail.com \\ Prof. Dr. Galdenoro Botura Junior \\ Universidade Estadual Paulista "Julio de Mesquita Filho" \\ galdenoro@gmail.com \\ Prof. Dr. Tomás Queiroz Ferreira Barata \\ Universidade Estadual Paulista "Julio de Mesquita Filho" \\ barata@faac.unesp.br
}

\begin{abstract}
Resumo: $\mathrm{O}$ artigo apresenta o desenvolvimento do design de mobiliário para habitações contemporâneas formuladas a partir da análise e caracterização dos modos de vida nas grandes e médias cidades propondo um novo conceito de moradia. A abordagem remete a reflexão conceitual do mobiliário interno aplicado ao espaço de morar com apenas $15 \mathrm{~m}^{2}$ de área útil, enfatiza o entendimento dos novos modos de vida e o estudo sobre as diferentes atividades desenvolvidas no espaço residencial. $O$ conceito do projeto se baseou no cubo mágico, com destaque para o movimento de rotação de uma das partes da habitação e com o objetivo de acessar quatro modos distintos ao longo do dia, que são: refeição, lazer, trabalho e descanso; além de considerar um redesenho de todos os mobiliários internos com base na ergonomia.
\end{abstract}

Palavras-chave: design, multifuncionalidade, habitação, mobiliário residencial.

\begin{abstract}
The article presents the development of furniture design for contemporary dwellings made from the analysis and characterization of the modes of life in large and medium cities by proposing a new concept of housing. The approach refers to conceptual reflection of internal furniture applied to the space of living with just $15 \mathrm{~m}^{2}$ of area, emphasizes the understanding of new ways of life and the study of the different activities carried out in the residential space. The concept of the project was based on the Rubik's cube, with emphasis on the movement of rotation of one of the parts of the housing and to access four distinct mode throughout the day, which are: meal, leisure, work and rest; in addition to considering a redesign of all internal securities based on ergonomics.
\end{abstract}


Keywords: design, multifunctionality, housing, residential furniture.

\section{INTRODUÇÃO}

A morada é, sem dúvidas, um espaço que merece atenção especial na atualidade. Pergunta-se quais são as características de uma "boa" residência? Qual é o comportamento humano e quais seus valores determinam esta característica? Como ao longo da história eram divididas as casas das metrópoles e colônias? Esses questionamentos levam a entender qual a relação à necessidade do homem e o espaço deixado para cada tarefa, ontem e hoje. O trabalho aqui apresentado proporciona um estudo comportamental de modo à por em prática conceitos que facilitam à habitação contemporânea aderindo aos valores atuais os contratempos do ser humano, bem como as mudanças sociais, políticas e econômicas, junto com nova forma de trabalho e as transformações das estruturas familiares, ao longo dos anos contribuíram decisivamente para um rearranjo do espaço.

Na casa urbana paulista oitocentista via-se um corredor que unia toda a casa, nos fundos encontrava um puxado lateral onde se alojava a cozinha e mais um espaço para os demais serviços da casa. As janelas somente eram postas na sala com vista para a rua e também na varanda que se abre para o quintal. O mobiliário e outros utensílios eram fabricados pelos próprios moradores ou pelos seus serviçais. As ferrovias inauguradas na década de 1870 fizeram da pequena cidade do planalto o destino preferencial de um número crescente de pessoas até tornar-se, um século mais tarde, a terceira mais populosa aglomeração urbana do planeta, segundo Tramontano, 2003.

Até 1945 a sociedade tinha vestígios da habitação antiga, pois a cozinha junto com a área de serviço era desvalorizada e sem prestigio algum, considerada local de trabalho escravo e nada mais. Mas a nova forma de morar veio para quebrar tabus existentes na família nuclear elitizada, a partir de uma divisão de cômodos com poucas paredes. São Paulo recebeu muitas influencias internacionais, em que uma quantidade significativa de apartamentos seguia o estilo de vida da Belle Epoque Francesa, contendo três repartições fixas internas: zona de rejeição (serviços), zona de prestígio (social) e zona de recolhimento (íntima). Ainda na mesma década de 60, a fase dos filmes hollywoodianos foi se espalhando até estar em contato com a sociedade brasileira através dos televisores da época. Isto acontece logo após em que os Estados Unidos ganha seu prestígio no período pós-guerra, tornando-se uma potencia mundial. Esta influência permitiu com que arquitetos e designers entrassem em ação reproduzindo exatamente o que os americanos difundiram, até com uso das mesmas palavras, como home office, hall, closet, living-room, entre outros termos específicos, segundo Tramontano 2003.

Por outro lado, a arquitetura japonesa que caracterizou por seus biombos dobráveis, baixela de cerâmica, entalhes e paisagismo sofisticado se adaptou a estas novas necessidades? Na casa não havia repartições, portanto a família desde o amanhecer ao anoitecer permanecia unida, e com isso o mobiliário japonês fazia a função das paredes ocidentais. Muitas vezes algumas mobílias tinham dois papéis, aparecendo assim a multifuncionalidade interna. Os principais materiais utilizados na 
construção eram madeira, terra, bambu e papel. No período pós-guerra esses materiais não caíram em desuso. Todavia, a Companhia de Habitação do Japão decretou o inicio da construção maciça de edifícios de apartamentos por todo país em 1995. Nos anos 60, duas leis foram elaboradas de modo a permitir a divisão de um imóvel, ou seja, concretizou os famosos condomínios; e autorizou o aumento da altura total dos edifícios, bem como o tamanho de área construída. Assim foram surgindo novas experimentações habitacionais, como o projeto da Nagakin Capsule Tower, em Tokyo no ano de 1972 e construído o Nexus World, na cidade de Fukuoka entre 1989 e 1991. Assim a estrutura familiar foi caminhando para o mesmo fim e com a mesma autonomia.

Paris foi a primeira a se preocupar com os estudos habitacionais. A família parisiense antiga era muito parecida com a família paulistana no século XIX, em que o casamento era monogâmico e com muitos filhos. Depois da Belle Epoque francesa caracterizada por muitas salas de requinte, e demasiado espaço para a moradia, houve a aparição dos cortiços, que por sua vez tomaram as ruas da cidade a abrigaram muitas famílias da classe média. Esse novo estilo parisiense de moradia comportava poucos móveis e objetos, não havendo muitas repartições e nem ornamentos. O banheiro era comunitário e a falta de higiene gerava doenças que foram tomando parte desse meio habitacional. Em 1851, com o investimento estatal inaugurou-se a Cité Napoléon, "um conjunto em torno de um pátio central, destinado a abrigar seiscentas pessoas em duzentas habitações de dois cômodos e cozinha". Água canalizada para cada "casa" e agentes higienistas permaneciam a disposição para ajudar na prevenção de algumas doenças. De 1880 a 1914 os franceses se depararam com um movimento modernista, mais conhecido como Haussmaniano, recheado de muitos arquitetos e engenheiros capazes de mudar conceitos. Já nos anos 70, a habitação segue com sua montagem rápida. Do coletivo ao individual, os containers com serviços hidráulicos e suas ossaturas de aço, poliéster, fibras de vidro e poliuretano foram o sucesso esperado exatamente por ser modular e de fácil transporte. Lava louças, lava roupas, freezers, televisão, tele-shopping, segurança eletrônica e outras maquinas fizeram o mesmo sucesso acompanhando a nova célula de morar. Já em Los Angeles (Hollywood), o "american way of life" seguiu fortemente influenciando os demais países. A independência financeira ali abordada fez com que desaparecessem os casarões e entrasse os apart-hoteis. O ferro, o concreto armado, o baquelite e o plástico eram os materiais da vez. Tudo isso permitiu com que a ArtDecó estivesse totalmente associada à sociedade industrial ascendente. Nos anos 30, no Brasil, a ArtDecó aparece em muitos monumentos e construções, como o edifício do Mapplin, edifício Columbus, cinema UFA Palace, Viaduto do Chá, e outros, todos em São Paulo. A forte influência dos Estados Unidos transformou o palco europeu em um palco completamente americanizado. A evolução das necessidades e das restrições de espaço levou ao movimento incessante das paredes, ou até mesmo a queda delas, promovendo atividades unificadas, de modo que foi possível mesclar as atividades, como: assistir TV, comer e receber visitas em uma mesma área. Por outro lado, o deslocamento para o local de trabalho já está, em parte, desaparecendo, devido aos problemas relacionados com a mobilidade urbana.

Toda essa transformação do espaço de morar está intimamente relacionada, também, com o tamanho, a estrutura e a função familiar. A mudança do papel social, 
principalmente da mulher, que passa a ter autonomia financeira, há a queda de natalidade, a opção do divórcio, além de filhos mais independentes, tem reflexos, que pode ser percebida através da constante mudança da forma de moradia. Ou seja, entra a percepção da necessidade, o que é preciso dentro de uma casa para que a sua função social seja atendida, e para cada uma delas, há uma especificação.

"a queda acentuada da fecundidade, o aumento da longevidade, a crescente inserção da mulher no mercado de trabalho, a liberação sexual, a fragilidade cada vez maior das uniões, o individualismo acentuado, etc, são tendências que vêm atuando no sentido de alterar o tamanho, a estrutura e a função da família." (BERQUÒ,

1989).

De modo a facilitar o uso do espaço onde ele é exíguo e, em função da condição humana atual, foi criada uma célula interativa, baseada na ideia do brinquedo cubo mágico e seus movimentos, adaptado ao autentico modo de vida da cidade. O cubo é considerado um brinquedo interativo e extremamente racional, e tem por finalidade a organização correta de suas cores. A partir dessas idéias foi elaborado um projeto que organiza o mobiliário interno com flexibilidade, mobilidade e autonomia do espaço, variar as configurações de acordo com as diferentes atividades exercidas no espaço de morar, incorporando multifuncionalidade, modularidade e redução espacial.

\section{A CÉLULA DE MORAR}

Um dos maiores problemas para se morar, encontrados hoje nos grandes centros urbanos, está relacionado com valor do metro quadrado. Além dos altos valores encontrados, principalmente nas regiões metropolitanas, existe também o problema do aumento populacional, que tem acentuado significativamente nos últimos tempos. Portanto, construir uma casa ou apartamento com grande área habitável tornou-se acessível para poucos. É nesse contexto que se torna necessário a otimização dos espaços, principalmente em apartamentos, que já chegaram a ter $9 \mathrm{~m}^{2}$ de área construída, localizados próximos da torre Eiffel em Paris. Em muitos lugares como Paris, Japão, e agora Brasil, verifica-se, cada vez mais este fenômeno, ou seja, a diminuição da metragem residencial pela falta de espaço. O mobiliário virou a repartição da casa, como ocorria no Japão, além de muitas vezes possuir dupla função. A proposta de conceito de moradia e o projeto Plug-in que está interligado nessa situação problema, vem buscando promover tal otimização. A ideia de uma casa que se adapta as necessidades humanas, utilizando justamente a mobilidade, como a de um cubo mágico, nada mais é do que reduzir espaço e também aperfeiçoá-lo.

A parte móvel do Plug-in é similar a um anel, que gira em torno de um eixo imaginário, oferecendo quatro configurações diferentes. Tal sistema, inspirado no movimento do cubo mágico, mantém em suas laterais duas partes fixas, uma com o módulo molhado (banheiro e cozinha), sendo a entrada da residência, e outra mais estreita, situada do outro lado do anel móvel, contendo uma grande janela. A figura 1 apresenta o conceito aqui descrito. 


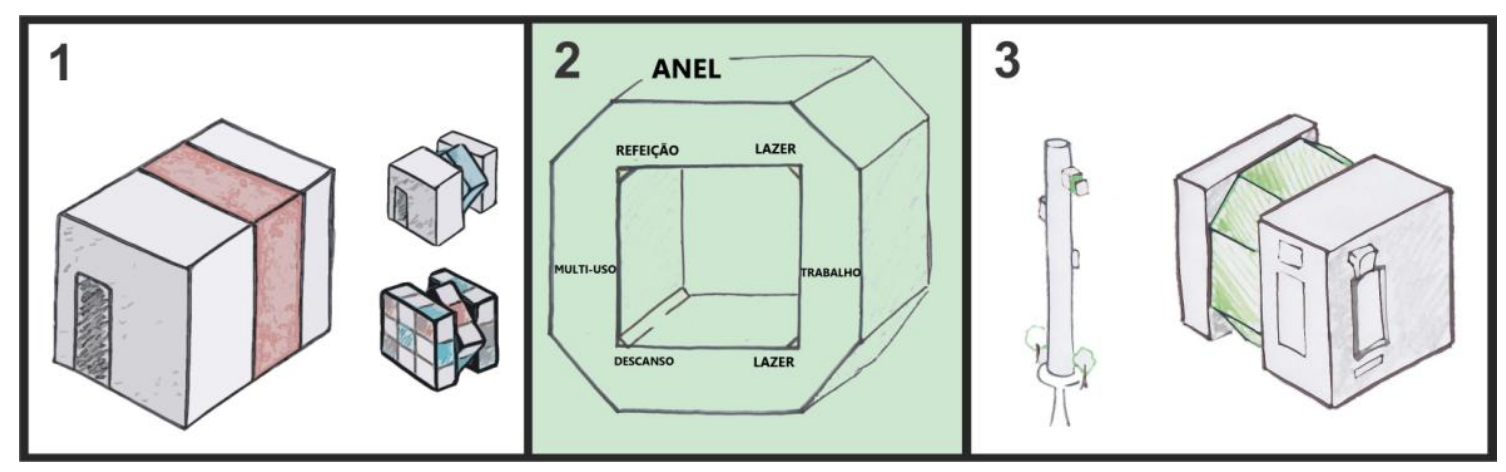

Figura 1 - Sketches

1-Esboço do funcionamento da célula; 2-Especificação dos quatro modos; 3-Modelo final da célula (casa) e cerne (prédio).

\subsection{Parte Móvel}

A parte móvel é constituída das áreas de trabalho, multi-uso, refeição, descanso e lazer, distribuídas ao longo do anel.

\subsubsection{Lazer}

As duas paredes do modo Lazer alojam partes do sofá que quando puxadas expandem-se para posteriormente se unirem, ocasionando o fechamento completo do espaço, através de um sistema baseado em uma porta pantográfica. O sofá consegue ter seu tamanho duplicado, no qual as partes direita e esquerda atingem em seu modo aberto de 1,20 metros. O conforto e a rigidez do móvel são conseguidos através do inflar automático de bolsas que ficam alojadas entre os vãos dos perfis. A janela, situada em uma das áreas fixas, além de promover a iluminação natural, pode ser utilizada como uma ampla tela de entretenimento (figura 2).

\subsubsection{Descanso}

A parede da parte móvel destinada ao modo Descanso encontra-se oposta à parede de refeição. Próximos ao chão estão instalados sensores, feitos de resina, que servirão como luminárias e, também, como botões de acionamento. Ao pressionar essas luminárias, o colchão sairá através de uma porta de acesso retangular, inflandose por completo, adquirindo assim forma e altura de cama, com medidas de 1,40 metros de largura por 2,10 metros de comprimento (figura 2).

\subsubsection{Trabalho}

O modo Trabalho tem apenas uma parede útil, oposta à parede multiuso. No programa deste modo é previsto o uso de notebooks, novas interfaces e derivados com acesso à internet. Existe uma mesa, em forma de meio círculo, encaixada em 60 centímetros, servindo como auxílio quando exposta (figura 2). 


\subsubsection{Refeição}

Para o modo Refeição, um ambiente com mesa e cadeiras. A altura da mesa é de 75 centímetros, o tampo tem 75 centímetros de largura por 55 centímetros de comprimento, recebendo uma aba adicional para aumentar seu tamanho. Duas cadeiras deverão sair da parede localizada próxima à mesa, através de braços articulados. Estes terão uma rotação no final, em que possibilitará à cadeira um giro de 90 graus, ficando mais confortável e facilitando o sentar. As cadeiras terão 45 centímetros de altura por 50 centímetros de largura, tamanho esse mais parecido com uma poltrona. Do chão sairão mais dois apoios, nos quais poderão ser acopladas mais cadeiras, completando assim a sala de refeição (figura 2).

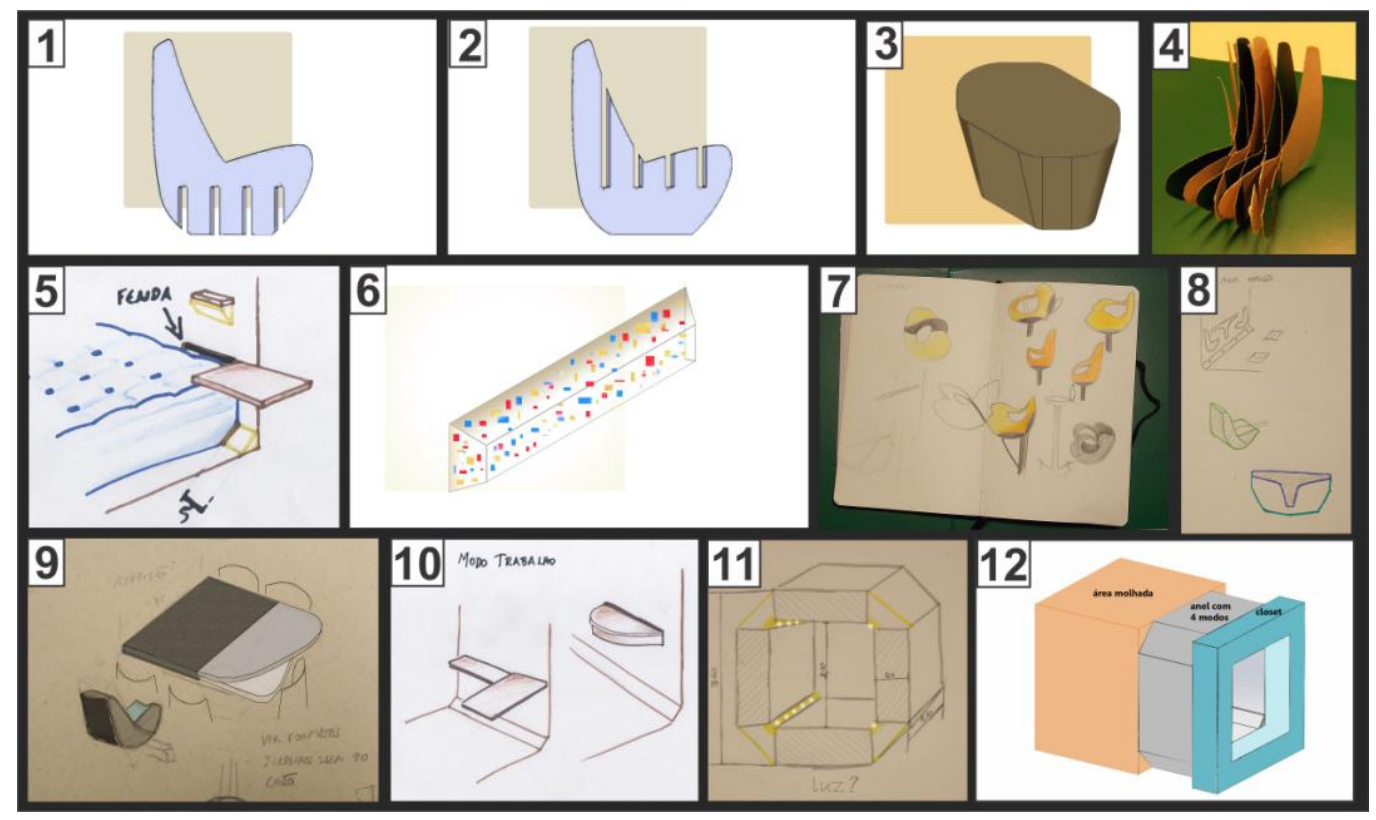

Figura 2 - Sketches dos quatro modos

1-Sofá (peça de encaixe x); 2-Sofá (peça de encaixe y); 3-Mesa de centro; 4-Modelo de encaixe feito em papel; 5-Modo descanso; 6-Luminária do modo descanso; 7Sketches de cadeiras; 8-Modo refeição; 9-Estudo das formas do modo refeição, 10Modo trabalho; 11-Estudo de iluminação; 12-Especificação da parte móvel.

\section{2. Área Fixa}

O closet é desenhado de forma a dispor de um eixo central com abas divisórias oferecendo um espaço de três colunas. Nessas colunas existe um sistema de encaixe das prateleiras para que sejam ajustadas conforme necessidade. Tal ajuste se dará da seguinte forma: cada prateleira irá conter um pino central, que se encaixará em um trilho com canaletas, possibilitando ao usuário modificar seu closet como precisar. Ao lado do closet principal haverá uma escada de acesso às sapateiras. Elas seguem uma medida de 45 centímetros de altura por 50 centímetros de diâmetro. 0 espaço de 50 centímetros poderá ser usado como um assento, facilitando assim a ação de calçar-se. Serão duas sapateiras, uma próxima a outra. Seguindo adiante, do outro lado da parede, surgirá a outra parte do closet. Embaixo das escadas existem dois compartimentos que servirão para guardar roupas de cama e banho. $O$ vidro da janela, que também está na parte fixa, possui capacidade para captar a energia solar e 
armazená-la em um dispositivo próximo a ele, podendo assim escurecer o ambiente e proporcionar privacidade (figura 3).

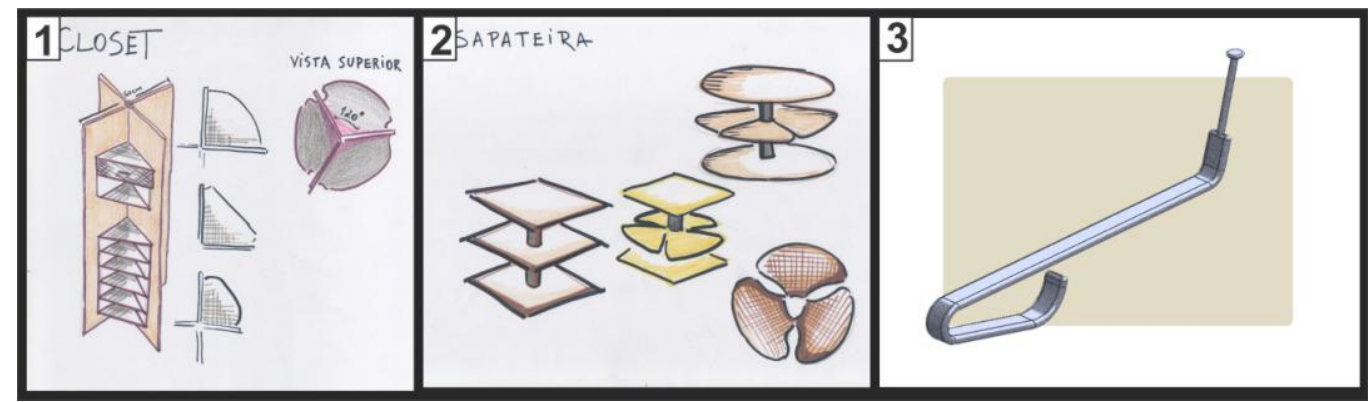

Figura 3 - Sketches dos móveis (área fixa) 1-Closet; 2-Sapateiras; 3-Cabide (closet).

\section{3. Área Molhada}

O módulo Banheiro demandou elevada precisão em relação à utilização do espaço interno. Haverá um compartimento redondo caracterizando a parte da ducha e os demais utensílios. O chuveiro terá o formato de um anel envolvendo o usuário durante o banho. Com uma parte da parede espelhada imantada, acessórios como saboneteiras, gancho para toalha e até mesmo um reduzido armário podem ser acoplados (figura 4).

O módulo Cozinha está dividido em três faixas. Seu modo fechado assemelhase a um bloco. A base de toda a cozinha possui $85 \mathrm{~cm}$ de altura. A faixa próxima ao teto pode ser aberta através de uma haste articulada que se projeta para a direita e desce até nivelar seu topo com a bancada da pia, tornando-se uma extensão para o preparo de alimentos. Com o intuito de não prejudicar a circulação da moradia, a projeção da bancada não ultrapassa os $60 \mathrm{~cm}$. A parte intermediária revelará a geladeira, sendo que através de um dispositivo localizado em sua maçaneta é possível acessar a cuba da cozinha, ao final do processo a geladeira cederá seu espaço por completo para dar lugar a pia. A parte inferior é fixa e possui diversos armários. A máquina de lavar louças utilizará um sistema no qual o primeiro ciclo de sua lavagem reutilizará a água que o usuário selecionou através da comporta no ralo da cuba, esta possui dois ralos, um que deverá escoar a água inutilizável e o outro que poderá reaproveitá-la. 


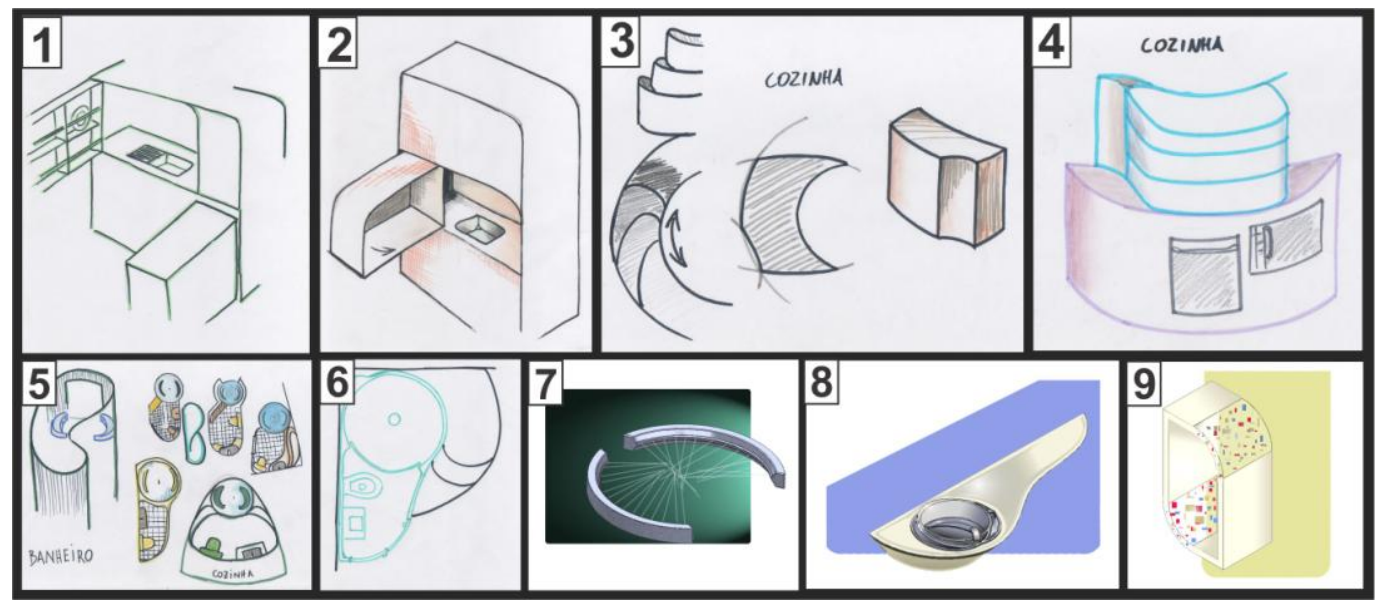

Figura 4 - Sketches da área molhada

1-Primeiro desenho (cozinha); 2-Segundo desenho (cozinha); 3-Terceiro desenho (cozinha); 4-Quarto desenho (cozinha); 5-Sketches do banheiro; 6-Desenho final da composição banheiro/cozinha; 7-Desenho da ducha; 8-Desenho da pia (banheiro); 9Desenho do nicho (banheiro).

\section{MATERIAIS PARA CONSTRUÇÃO}

A superfície externa do habitáculo é revestida de liga metálica, auxiliada por isolantes termo-acústicos, um composto de lã de vidro. A parte fixa estrutural interna é composta de blocos tridimensionais de concreto pré-moldado. As cores podem ser configuráveis, com emprego de tintas nanotecnologias capazes de mudar sua matiz, tom ou saturação. O módulo molhado deve ser de material não absorvente, liso e resistente, comparável à fibra de vidro. A porta de entrada do box é feita de vidro curvo resinado comum. Na parte móvel, as divisões internas das funções são de MDF (medium density fiberboard) revestido com resina melamínica de baixa pressão em regiões que apresentem um grau de usinagem mais complexo e MDP (medium density particleboard) com o mesmo revestimento em locais que a resistência ao empenamento se torna uma condição fundamental para a qualidade do mobiliário (ex. grandes horizontais sem apoio).

As quatro paredes internas da parte móvel serão de vidro antirrisco com a capacidade de se tornar espelhado. A parte fixa próxima à janela se constitui de MDF nos armários laterais e de chão. O painel de vidro utilizado na janela possui tecnologias já em uso na atualidade, que capta a energia solar e a armazena em baterias. Esta tecnologia permite controlar a luminosidade no espaço interno, pois possui "cristais" capazes de alterar o ângulo de refração da luz externa, aumentando a entrada de luz solar ou luminosidade do céu. Outra característica é a de projetar imagens substituindo a televisão ou qualquer dispositivo que requeira uma tela. Por fim, para detalhes de interface do usuário com o mobiliário da morada e o módulo molhado, prevê-se o uso de resina poliéster cristal.

Como conexão de energia, água e esgoto da casa, apresenta uma única região para fazê-lo: logo abaixo da porta de entrada, e com o mesmo intuito, acima da passagem dos habitantes encontra-se o gancho de fixação dessa célula de morar com um cerne, o qual serve como estrutura parecida de um prédio contendo os elevadores e demais tubulações necessárias. Quanto às configurações luminosas há quatro barras 
principais na parte móvel do ambiente e iluminação adicional no módulo molhado e closet.

\section{MODELOS E MAQUETES}

Uma vez definidos os desenhos foi feita a modelagem 3D da estrutura, móveis e utensílios no software SolidWorks 2012 e Studio 3DMax, de modo que se pudesse visualizar as dimensões reais do projeto, conforme apresenta a figura 5, e a confecção dos mock-ups, conforme figura 6, onde utilizou-se chapa de MDF (medium density fiberboard), a qual foi cortada, furada, colada e pintadas de acordo com o projeto. Os parafusos exerceram as funções de encaixar e estabilizar as três partes da célula de morar. No acabamento foi utilizado lixas até atingir uma pintura lisa e uniforme. Para a confecção da maquete foram utilizados canos de PVC, papel cartão e cola quente, bucha e palitos para confecção dos arbustos, placa de MDF para base do projeto e pintura para finalização. As células de morar foram feitas de papel que receberam inicialmente o desenho planificado com medidas reduzidas e depois foram dobradas e coladas, como em um processo de origami (Figura 6). 


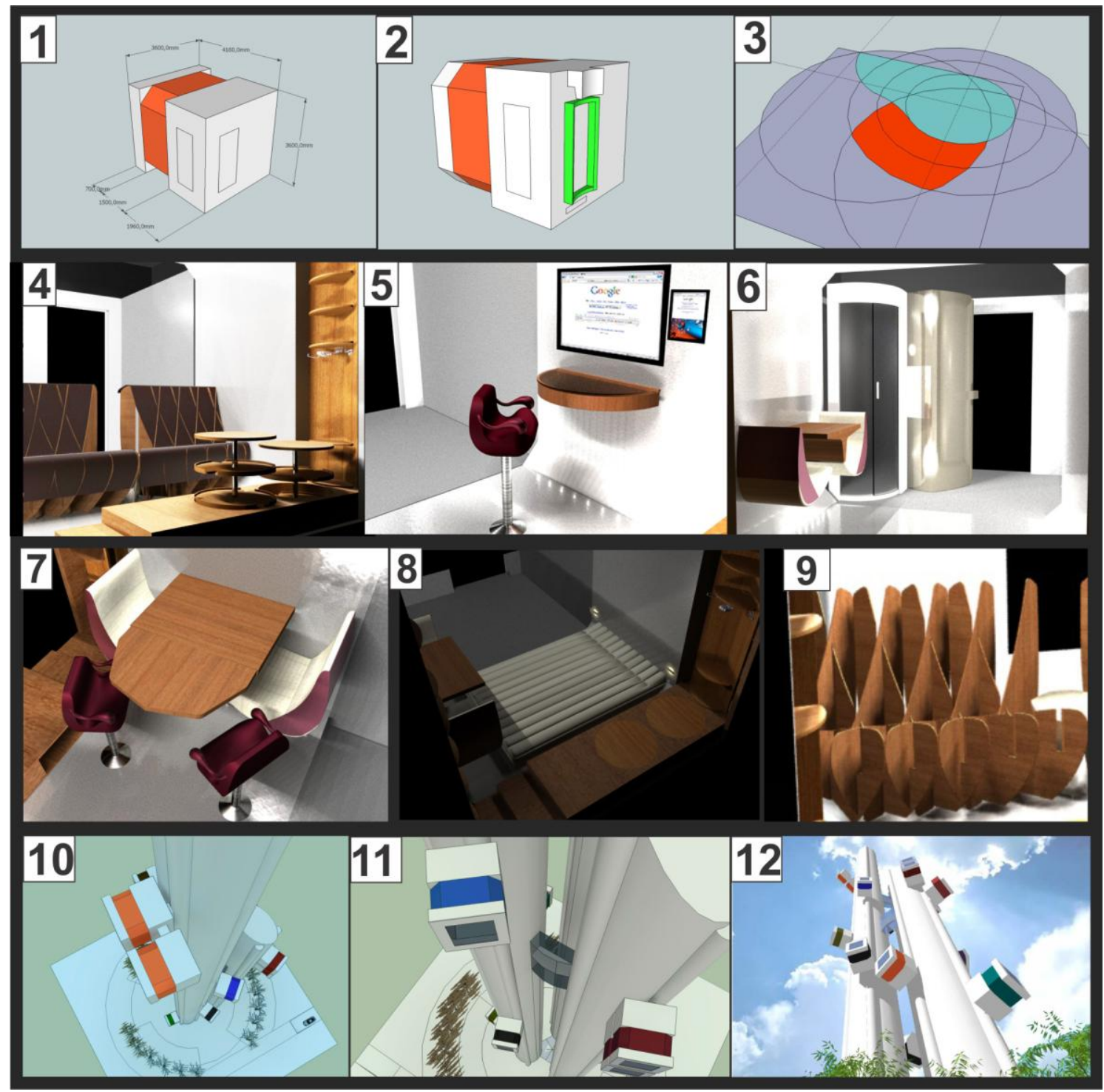

Figura 5 - Render final do projeto Plug-in

(Elaborados pelo primeiro autor, com base nas pesquisas realizadas)

1,2-Sketches da célula; 3-Demarcação do Banheiro(verde) e da cozinha (vermelho); 4-Render do modo lazer junto com a vista da parte fixa; 5-Render do modo trabalho;

6-Render do modo refeição junto com a vista da área fixa; 7-Render do modo refeição; 8-Render do modo descanso; 9-Render do sofá (estrutura); 10,11,12-Render do prédio (cerne) 

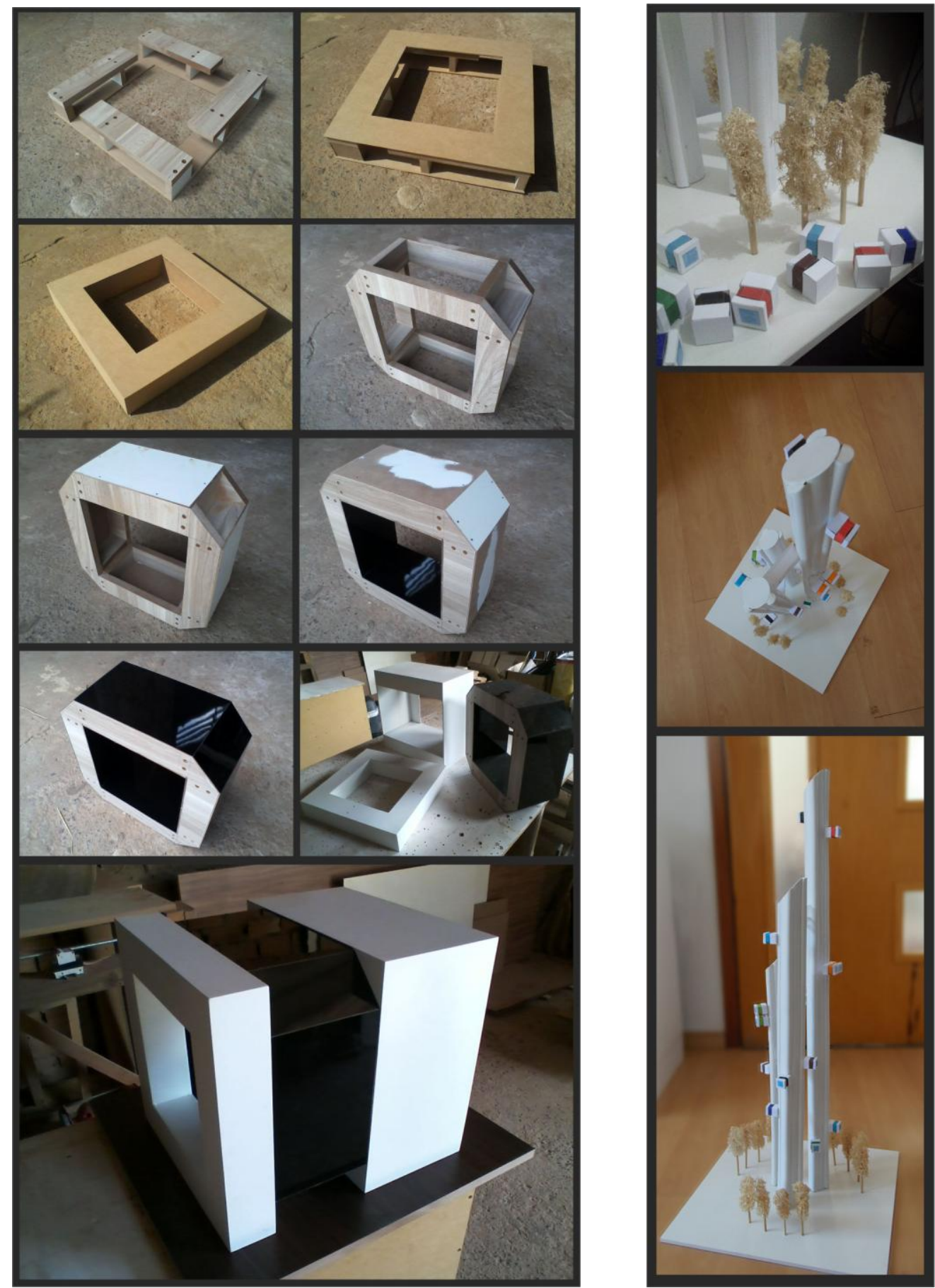

Figura 6 - Maquetes de simulação do projeto Plug-in

Célula - feita de MDF e fórmica

Cerne - feito de PVC, papel dobradura, bucha e MDF

\section{CONCLUSÃO}

Para o desenvolvimento da pesquisa constatou-se a existência de novos hábitos cotidianos, que as mudanças na relação espaço/tempo e uma nova dinâmica de morar são tendências que devem ser incorporadas construção de novas espaços, tendo como consequência a exigência de novos móveis que se adequem a este novo conceito de moradias onde se privilegia as localizações urbanas, a otimização do espaço de morar 
para um número, cada vez maior, de um número reduzido de pessoas. O projeto aqui apresentado é uma alternativa de mobília integrada, inteligente e viável frente a um novo conceito de moradia e a tantas transformações das metrópoles na atualidade. Assume como requisito de projeto a visível e ascendente minimização dos espaços internos habitacionais como mote para um exercício de criatividade no desenvolvimento do design de mobiliário adequado ao espaço residencial construído. Constata-se que é possível desenvolver mobiliários com qualidade em um espaço considerado reduzido ou "mínimo". Este reafirma conceitos de racionalização, flexibilidade, automação e otimização no design de mobiliário considerando a máxima adequação dos espaços de morar nas grandes e médias cidades brasileiras.

\section{REFERÊNCIAS}

TRAMONTANO, M. . Alice no país da especulação imobiliária: habitação e modos de vida na cidade de São Paulo. Cidades. Comunidades e Territórios, Lisboa, Portugal, v. 6, p. 75-82, 2003. Disponível em: http://www.nomads.usp.br/site/livraria/livraria.html Acessado em: 18/08/2012.

TRAMONTANO, M. ; BENEVENTE, V. A. . Comportamentos \& espaços de morar: leituras preliminares das e-pesquisas Nomads. In: ENTAC'04, 2004, São Paulo. Anais, 2004. $210 \mathrm{~mm} \times 297 \mathrm{~mm}$. $10 \mathrm{pl}$ Disponível em: http://www.nomads.usp.br/site/livraria/livraria.html.Acessado em: 17/08/2012.

TRAMONTANO, M. . Apartamentos em São Paulo: brevíssimo exame de uma históriacontroversa. In: revista AU. Arquitetura e Urbanismo, v. abril, p. 68-71, 2006. Disponível em:http://www.nomads.usp.br/site/livraria/livraria.html Acessado em: $17 / 08 / 2012$.

TRAMONTANO, M. . Interactive Living-Spaces: 12 Preliminary Notes. In: NIETO, I.; VEGA, R.; TELLO, I.. (Org.). Installing: art and technology / Instalando: arte y tecnologia. Santiago: Troyano, 2007, v. , p. 143-147. Disponível em: http://www.nomads.usp.br/site/livraria/livraria.html Acessado em: 17/08/2012.

TRAMONTANO, M. Habitações, metrópoles e modos de vida. Por uma reflexão sobre o espaço doméstico contemporâneo. 3o. Prêmio Jovens Arquitetos, categoria "Ensaio Crítico". São Paulo: Instituto dos Arquitetos do Brasil / Museu da Casa Brasileira, 1997. $210 \mathrm{~mm} \quad x \quad 297 \mathrm{~mm} . \quad 10$ p. Ilustr. Disponível em: http://www.nomads.usp.br/site/livraria/livraria.html Acessado em: 18/08/2012.

TRAMONTANO, M. ; SAKURAI, T. ; NOJIMOTO, C. ; BARBOSA, L. L. ; ANTUNES, R..Ecomaterialidade para habitações reduzidas. In: ENTAC'04. São Paulo: ANTAC, 2004. 210mmx297mm. $10 \quad$ p. Disponível em: http://www.nomads.usp.br/site/livraria/livraria.html Acessado em: 17/08/2012.

TRAMONTANO, M. . Habitação urbana no Japão. Um breve olhar/A brief overview of urban housing in Japan.. 1995. São Carlos: EESC-USP, 1996. 210mmX210mm. 54 p. Ilustr. Fotocópia p\&b.Disponível em: http://www.nomads.usp.br/site/livraria/livraria.html Acessado em: 17/08/2012. 
NETO, Anderson Passos. Hollywood: Metrópole, Modo de Vida e o Art Decó. Trabalho final de Pós-Graduação. São Carlos. Disponível em http://www.nomads.usp.br/disciplinas/SAP5846/mono_aderson.pdf Acessado em: $17 / 08 / 2012$.

SAKURAI, T. Flats ou habitação reconfigurável. Relatório de Iniciação Científica. Bolsa FAPESP. São Carlos: NOMADS EESC-USP, 2002. 200mm×250mm. 75 p., Ilustr. Fotocópia p\&b. Disponível em: http://www.nomads.usp.br/site/livraria/livraria.html Acessado em: 18/09/2012.

SPERLING, D. .Habitação social francesa. Volume 1. David Sperling. Relatório parcial de Iniciação Científica. Bolsa CNPq-Pibic. São Carlos: EESC-USP, 1997. 200mm×250mm. 75 p., Ilustr. Fotocópia p\&b. Disponível em: http://www.nomads.usp.br/site/livraria/livraria.html Acessado em: 17/08/2012 